\title{
Influência da Temperatura e do Tempo de Inoculação das Sementes de Algodão na Transmissibilidade de Colletotrichum gossypii var. cephalosporioides*
}

\author{
Dejânia V. Araújo**, Edson A. Pozza, José C. Machado, Elisandra B. Zambenedetti, Fabiane A. O. \\ Celano, Enia M. Carvalho \& Valquíria N. Camargos
}

Departamento de Fitopatologia, Universidade Federal de Lavras, CEP 37200-000, Lavras, MG, e-mail: eapozza@ufla.br

(Aceito para publicação em 20/10/2005)

Autor para correspondência: Edson Ampélio Pozza

ARAÚJO, D.V., POZZA, E.A., MACHADO, J.C., ZAMBENEDETTI, E.B., CELANO, F.A.O., CARVALHO, E.M. \& CAMARGOS, V.N. Influência da temperatura e do tempo de inoculação das sementes de algodão na transmissibilidade de Colletotrichum gossypii var. cephalosporioides. Fitopatologia Brasileira 31:035-040. 2006.

\section{RESUMO}

A transmissibilidade de Colletotrichum gossypii var. cephalosporioides foi estudada em diferentes temperaturas utilizando sementes de algodoeiro (Gossypium hirsutum) inoculadas com diferentes tempos de exposição ao patógeno. O experimento consistiu de seis tratamentos, sendo três tempos de exposição (36, 72 e 108 h) das sementes, inoculadas e não inoculadas com o fungo, testados em temperaturas de 15, 20, 25 e $30 \pm 2{ }^{\circ} \mathrm{C}$. Os tratamentos provenientes de sementes não inoculadas com o fungo foram utilizados como testemunhas. Os tempos de inoculação apresentaram diferença na incidência e na porcentagem da semente coberta com propágulos do patógeno (PSCPP), sendo o maior valor observado no tempo de 108 h, com conseqüências na germinação e porcentagem de plantas sobreviventes. Os tempos de 36 e 72 h não apresentaram diferença entre si. Temperaturas mais baixas e a maior quantidade de inóculo nas sementes proporcionaram redução na germinação e porcentagem de plantas sobreviventes. A intensidade da doença não foi influenciada pelo tempo de exposição, no entanto, a temperatura foi fator determinante para a transmissibilidade do patógeno, sendo a incidência e a severidade maiores com o aumento desta. O condicionamento osmótico estimulou o desenvolvimento fúngico, sendo observadas maior incidência e severidade da doença no tempo de $108 \mathrm{~h}$.

Palavras-chave adicionais: Gossypium hirsutum, restrição hídrica, sementes, transmissibilidade, ramulose.

\section{ABSTRACT}

The influence of temperature and time of seed inoculation in the transmission of Colletotrichum gossypii var. cephalosporioides

The transmission of Colletotrichum gossypii var. cephalosporioides by cotton (Gossypium hirsutum) seeds was studied at different temperatures using seeds inoculated at different times of exposure to pathogen grown in osmotic agar medium. The experiment consisted of six treatments, three exposure times (36, 72 and $108 \mathrm{~h}$ ) of seeds to osmotic medium with and without fungus, and tests at temperatures of 15, 20, 25 and $30 \pm 2{ }^{\circ} \mathrm{C}$. Treatments without the fungus were used as control. Inoculation periods were implicated in differences in the incidence and percentage of pathogens in seeds. The highest rates were observed when seeds were exposed for $108 \mathrm{~h}$, with consequences for the germination and percentage of surviving plants. No statistical difference was detected at 36 and $72 \mathrm{~h}$. Lower temperatures and more inoculum of seeds led to a lower percentage of germination and surviving plants. Disease intensity was not influenced by inoculation periods. However, temperature was an important factor affecting the transmissibility of pathogen; an increase of incidence and severity led to an increase in the transmissibility of the pathogen. Osmotic conditioning of seeds stimulated fungus development; a high incidence and severity of disease were found when inoculation of seeds was done at $108 \mathrm{~h}$.

Additional keywords: Gossypium hirsutum, water restriction, seeds, transmissibility, ramulose.

\section{INTRODUÇÃO}

A transmissão de patógenos da semente para a parte aérea da planta é influenciada pela temperatura, porém, é preciso levar em consideração o efeito desta variável microclimática sobre as taxas de germinação e de emergência de sementes e sobre a interação patógeno-hospedeiro (Shah

\footnotetext{
*Parte da Dissertação de Mestrado do primeiro autor. Universidade Federal de Lavras (2004).

**Bolsista FAPEMIG.
}

\& Bergstrom, 2000). Além desses fatores, o potencial de inóculo e sua localização na semente são de extrema importância no processo infeccioso (Tanaka \& Machado, 1985).

A disseminação de Colletotrichum gossypii South var. cephalosporioides S.A. Costa bem como o progresso da ramulose são influenciados por variáveis ambientais, principalmente a temperatura e a umidade relativa (Kimati, 1980). Em regiões com temperaturas elevadas, a viabilidade dos esporos e a formação de lesões são reduzidas, culminando 
com a redução no progresso da doença. Por outro lado, a maior incidência de tombamento de plântulas, em pré e pósemergência, é atribuído a baixas temperaturas no solo durante o período de germinação. Nessas condições, ocorre aumento de exsudação de açúcares e aminoácidos e, conseqüentemente, aumento de microrganismos patogênicos e saprofíticos (Tanaka, 1995).

A inoculação de sementes, além de possibilitar a ocorrência de sintomas, auxilia em estudos de patogenicidade, resistência do hospedeiro, controle, dentre outros (Tanaka et al., 1989; Tanaka \& Menten, 1991). Além do método de inoculação, o tempo de contato das sementes com o patógeno é de grande importância para obter sementes com diferentes níveis de inóculo (Machado \& Machado, 2002). Vários trabalhos elucidaram o efeito de C. gossypii var. cephalosporioides em sementes inoculadas (Tanaka \& Menten, 1991; Prado et al., 2002), no entanto, não relataram sobre níveis de inóculo nas sementes e a influência da temperatura na transmissibilidade do patógeno. Diante disso, o presente trabalho teve por objetivos, avaliar o efeito do tempo de exposição das sementes, em meio com restrição hídrica, na incidência e na área da semente coberta por propágulos de C. gossypii var. cephalosporioides e o efeito de diferentes temperaturas e tempos de exposição das sementes na porcentagem de germinação e de plântulas sobreviventes e na expressão da intensidade da ramulose em plântulas de algodoeiro.

\section{MATERIAL E MÉTODOS}

O trabalho foi conduzido em câmaras de crescimento vegetal localizadas nos Departamentos de Fitopatologia e de Agricultura da Universidade Federal de Lavras.

Foram utilizadas sementes da linhagem NU 15, safra 2002/2003, do Instituto Agronômico de Campinas/SP, deslintadas com ácido sulfúrico (PA) e submetidas à assepsia com hipoclorito de sódio 2\%, por 1 min. A germinação inicial das sementes em rolo de papel (Brasil, 1992) foi de 97,5\%, não sendo verificada, no teste de sanidade ('blotter test'), a presença de C. gossypii var. cephalosporioides.

Utilizou-se o método da restrição hídrica para inocular as sementes com C. gossypii var. cephalosporioides (Carvalho, 1999; Costa, 2000; Machado et al., 2001). Colônias puras do fungo desenvolveram-se em placas de Petri contendo manitol (46,3 g/l) em meio BDA, com potencial hídrico ajustado para -1,0 MPa, segundo cálculo do Software SPPM (Michel \& Radcliffe, 1995). As culturas foram mantidas em incubação à temperatura de $25 \pm 2{ }^{\circ} \mathrm{C} \mathrm{e}$ fotoperíodo de $12 \mathrm{~h}$ por três dias, quando as sementes foram colocadas em contato com o fungo, sendo estas incubadas por períodos de 36, 72 e 108 h, em delineamento experimental inteiramente casualizado com oito repetições. Cada repetição foi constituída de uma placa de Petri de 15 cm contendo 25 sementes. Para avaliar o efeito do condicionamento osmótico na qualidade fisiológica, sementes foram mantidas em placas contendo meio ágar- água e manitol (-1,0 $\mathrm{MPa}$ ) sem a presença do fungo, em cada tempo de exposição. Ao serem retiradas do meio com restrição, as sementes foram secas ao ar por 24 h. Esses tratamentos foram testados por meio da análise sanitária e fisiológica das sementes.

$\mathrm{Na}$ análise sanitária, utilizou-se a temperatura de $20^{\circ} \mathrm{C}$ por sete dias, com fotoperíodo de 12 h. Após esse período, avaliou-se a incidência e a porcentagem da semente coberta com propágulos do patógeno (PSCPP).

Na análise fisiológica das sementes e na avaliação da intensidade da doença foi montado experimento em esquema fatorial $3 \times 2 \times 4$. Os fatores foram tempo de exposição, sementes inoculadas e não inoculadas com o patógeno e temperatura. Os tempos de exposição das sementes foram de 36, 72 e 108 h. As temperaturas, simuladas em câmaras de crescimento climatizadas, foram de 15, 20, 25 e $30 \pm 2{ }^{\circ} \mathrm{C}$ com fotoperíodo de $12 \mathrm{~h}$. Realizou-se a semeadura em caixas plásticas (49 x 28 x $9 \mathrm{~cm}$ ) contendo substrato composto de solo e areia na proporção 2:1, previamente tratado com brometo de metila. Em cada caixa foram semeadas 50 sementes, totalizando 200 sementes/tratamento. A análise fisiológica consistiu em avaliar a porcentagem de germinação e de plântulas sobreviventes. A porcentagem de germinação foi determinada quando o número de plântulas emergidas estabilizou em cada temperatura, sendo consideradas germinadas as plântulas cujos cotilédones encontravam-se a 1,0 cm do nível do solo. Aos 28 dias da semeadura determinou-se a porcentagem de plântulas sobreviventes. Para determinar a intensidade da ramulose, foram avaliadas a incidência - porcentagem de plântulas com sintomas da doença; e a severidade - obtida por meio de escala de notas ( 0 = plântulas sadias; 1 = lesão foliar; 2 = lesão no hipocótilo; 3 = lesão foliar e no hipocótilo; 4 = plântulas mortas). Essas notas foram ponderadas em relação à média utilizando-se o índice de Mckinney (1923).

As análises estatísticas foram realizadas utilizandose os programas SAS (Statistical Analysis System) e SISVAR (Ferreira, 2000). As variáveis significativas no teste F, da análise de variância foram comparadas pelo teste de Tukey $(\mathrm{P} \leq 0,05)$. No caso dos tempos de exposição e sementes inoculadas ou não, foi realizado o ajuste de equações de regressão para a temperatura.

\section{RESULTADOS E DISCUSSÃO}

A interação tempo de exposição e sementes inoculadas e não inoculadas com o patógeno, avaliado no teste de sanidade, não foi significativa para a incidência de C. gossypii var. cephalosporioides nas sementes, sendo os fatores analisados isoladamente. Contudo, esse efeito foi significativo para PSCPP.

Observou-se maior incidência e PSCPP no tratamento submetido ao tempo de 108 h de exposição das sementes ao patógeno quando comparado com os tempos 36 e 72 h, que não diferiram entre si (Tabela 1). Nas sementes précondicionadas sem o patógeno, não houve diferença. Porém, 
em todos os tempos de exposição detectou-se a presença do patógeno, mesmo não o tendo sido antes do pré-condicionamento. C. gossypii var. cephalosporioides provavelmente encontrava-se nas sementes em níveis baixos e foi estimulado durante o pré-condicionamento, possibilitando assim, a detecção deste mesmo após $36 \mathrm{~h}$ de exposição das sementes ao meio osmoticamente modificado. Em trabalho para avaliar a qualidade fisiológica e sanitária de sementes de cebola, Nunes et al. (2000) verificaram maior estímulo no crescimento fúngico nas sementes osmoticamente modificada.

A inoculação das sementes por restrição hídrica foi eficiente e o tempo de exposição destas ao patógeno permitiu obter sementes com, no mínimo, 43\% de incidência. Essa eficiência também foi comprovada por Costa (2000) em sementes de feijão inoculadas com Fusarium oxysporum Schlechtend Fr. f. sp. phaseoli Kendrick \& Snyder nos tempos de 36, 72, 108 e 144 h, na qual a incidência do patógeno foi maior com o aumento do tempo de exposição das sementes, sendo observado valores de $24,39 \%$ e $70,06 \%$ para o menor e o maior tempo, respectivamente. Da mesma forma, Tanaka et al. (1989) observaram maior incidência quando se aumentou o tempo de exposição das sementes a C. gossypii var. cephalosporioides, de 12 para 48 h. Segundo os autores, o aumento do tempo de exposição proporcionou maior penetração do patógeno nas sementes. Em inoculação de sementes de feijão com Xanthomonas campestris pv. phaseoli (Smith) Dye., Valarini \& Menten (1991) observaram a contaminação de $100 \%$ das sementes logo após o contato com o patógeno, porém a infecção de $100 \%$ destas só foi observada a partir de 36 h de contato da bactéria com a semente.

Não houve interação significativa entre tempo de exposição, sementes inoculadas e não inoculadas com o patógeno e temperatura, tanto para as variáveis da análise fisiológica das sementes quanto para a intensidade da doença.

As porcentagens de germinação das sementes e de plântulas sobreviventes foram semelhantes nos tempos de 36 e 72 h, reduzindo no tempo de 108 h de exposição das sementes (Tabela 2). De acordo com Tanaka \& Machado (1985), a quantidade de inóculo presente na semente influencia a germinação e a transmissão de patógenos. Estes, quando associados à semente, podem ser grandes causadores de morte em pré e pós-emergência de plântulas, reduzindo, portanto, a porcentagem de germinação (Tanaka, 1994). O maior tempo de exposição favoreceu o aumento da infecção das sementes, conseqüentemente, houve redução na germinação. As plântulas emergidas no tempo de exposição de 108 h sofreram maior pressão do inóculo presente nas sementes, refletindo em menor porcentagem de plântulas sobreviventes.

Maiores tempos de condicionamento osmótico, aliados à presença de fungo, também proporcionaram menor redução na germinação das sementes. Costa et al. (2002) observaram redução na germinação de sementes de feijão inoculadas com $F$. oxysporum f. sp. phaseoli quando o período de inoculação aumentou de 0 até 144 h. Da mesma forma, em estudos com $X$. campestris pv. phaseoli inoculada em sementes de feijoeiro (Phaseolus vulgaris L.), observouse redução de $10 \%$ na germinação a partir de $36 \mathrm{~h}$ de contato com a bactéria (Valarini \& Menten, 1991). Apesar das particularidades de cada patossistema, os resultados observados corroboram com os obtidos no presente trabalho.

Quanto ao efeito da interação temperatura e sementes inoculadas e não inoculadas com o fungo foi observada maior germinação nas temperaturas de 15 e $20^{\circ} \mathrm{C}$ nas sementes não inoculadas, com diferença de $74,9 \%$ e $49,9 \%$, respectivamente, em relação às sementes inoculadas (Tabela 3). As temperaturas de 25 e $30{ }^{\circ} \mathrm{C}$ não apresentaram diferenças entre os tratamentos com e sem inoculação, sendo observados valores acima de 80\% na germinação. Em todas as temperaturas, a porcentagem de plântulas sobreviventes foi maior nos tratamentos sem inoculação. A redução em 100\% e 97\% no número de plântulas sobreviventes nas temperaturas de 15 e $20^{\circ} \mathrm{C}$, respectivamente, foi atribuída ao patógeno devido à ocorrência de tombamento e morte de plântulas, observados nos tratamentos inoculados. A presença do mesmo foi confirmada no reisolamento a partir de plântulas sintomáticas. Tanaka (1994) também observou o mesmo comportamento ao testar temperaturas de préresfriamento (nove dias a $10^{\circ} \mathrm{C}$ seguidos de três dias a $30^{\circ} \mathrm{C}$ ) e de $20^{\circ} \mathrm{C}$ na germinação de sementes de algodoeiro em solo naturalmente infestado por patógenos causadores de

TABELA 1 - Porcentagem de incidência e da semente de algodoeiro (Gossypium hirsutum) coberta por propágulos (PSCPP) de Colletotrichum gossypii var. cephalosporioides (Cgc), em função do tempo de exposição das sementes ao patógeno

\begin{tabular}{lccc}
\hline \hline Tempo de & Incidência & \multicolumn{2}{c}{ PSCPP (\%)* } \\
\cline { 3 - 4 } Exposição (h) & $(\%) *$ & com Cgc & sem Cgc \\
\hline 36 & 43,50 b & 46,67 b A & 0,33 a B \\
72 & 43,25 b & 49,50 b A & 1,83 a B \\
108 & 51,00 a & 72,50 a A & 4,67 a B \\
CV (\%) & 12,33 & \multicolumn{2}{c}{18,04} \\
\hline
\end{tabular}

*Médias com mesma letra, minúscula na coluna e maiúscula na linha, não diferem entre si pelo teste de Tukey $(\mathrm{P} \leq 0,05)$.

TABELA 2 - Porcentagem de germinação de sementes de algodoeiro (Gossypium hirsutum) inoculadas e não inoculadas com Colletotrichum gossypii var. cephalosporioides (Cgc) e de plântulas sobreviventes, em função do tempo de exposição das sementes ao patógeno

\begin{tabular}{lcc}
\hline \hline $\begin{array}{l}\text { Tempo de } \\
\text { Exposição (h) }\end{array}$ & Germinação (\%)* & $\begin{array}{c}\text { Plântulas sobreviventes } \\
(\%) *\end{array}$ \\
\hline 36 & $77,0 \mathrm{a}$ & $58,1 \mathrm{a}$ \\
72 & $75,0 \mathrm{a}$ & $56,3 \mathrm{a}$ \\
108 & $68,0 \mathrm{~b}$ & $46,4 \mathrm{~b}$ \\
\hline $\mathrm{CV}(\%)$ & 12,15 & 14,25 \\
\hline
\end{tabular}


TABELA 3 - Porcentagem de germinação de sementes de algodoeiro (Gossypium hirsutum) inoculadas e não inoculadas com Colletotrichum gossypii var. cephalosporioides (Cgc) e de plântulas sobreviventes, em função da temperatura

\begin{tabular}{lccccc}
\hline \hline \multirow{2}{*}{$\begin{array}{l}\text { Temperatura } \\
\left({ }^{\circ} \mathbf{C}\right)\end{array}$} & \multicolumn{2}{c}{ Germinação $(\%) *$} & & \multicolumn{2}{c}{$\begin{array}{c}\text { Plântulas } \\
\text { sobreviventes }(\%) *\end{array}$} \\
\cline { 2 - 3 } \cline { 5 - 6 } & com Cgc & sem Cgc & & com Cgc & sem Cgc \\
\hline 15 & $7,3 \mathrm{~b}$ & $82,2 \mathrm{a}$ & & $0,0 \mathrm{~b}$ & $82,5 \mathrm{a}$ \\
20 & $41,3 \mathrm{~b}$ & $91,2 \mathrm{a}$ & & $1,8 \mathrm{~b}$ & $85,1 \mathrm{a}$ \\
25 & $88,6 \mathrm{a}$ & $93,6 \mathrm{a}$ & & $38,1 \mathrm{~b}$ & $96,1 \mathrm{a}$ \\
30 & $90,0 \mathrm{a}$ & $92,6 \mathrm{a}$ & & $33,2 \mathrm{~b}$ & $92,2 \mathrm{a}$ \\
\hline $\mathrm{CV}(\%)$ & \multicolumn{2}{c}{12,15} & & \multicolumn{2}{c}{14,25} \\
\hline
\end{tabular}

*Médias com mesma letra, na linha, não diferem entre si pelo teste de Tukey $(\mathrm{P} \leq 0,05)$.

tombamento. Nessas condições, a germinação foi de $56,5 \%$ e $60 \%$, respectivamente, sendo a redução drástica na germinação, em todas as temperaturas, atribuída a $C$. gossypii.

Houve aumento tanto da porcentagem de germinação quanto de plântulas sobreviventes quando a temperatura variou de 15 para $30^{\circ} \mathrm{C}$ (Figura 1). Esse aumento certamente está relacionado à menor velocidade de germinação observada em baixas temperaturas, permanecendo a semente por maior tempo em contato com o patógeno (Tanaka \& Machado, 1985). O crescimento de plântulas expostas a baixas temperaturas é menor, conseqüentemente, tanto a rigidez quanto a espessura da parede celular serão menores, possibilitando maior penetração. Além disso, em temperaturas baixas há maior predisposição à ocorrência de tombamento devido a maior exsudação de açúcares de sementes ou raízes que favorecem o crescimento e a infecção de patógenos (Tanaka, 1995). Por outro lado, as sementes apresentam capacidade germinativa em limites bem definidos de temperaturas, característicos de cada espécie (Bewley \& Black, 1994). Sendo assim, temperaturas favoráveis possibilitam o desenvolvimento e a emergência de plântulas em curto período de tempo de maneira a reduzir a atuação de patógenos responsáveis por morte em préemergência (Maude, 1996).

Avaliando-se a incidência e a severidade da doença, observou-se efeito significativo da interação tempo de exposição e fungo (sementes inoculadas e não inoculadas) e na interação temperatura e fungo para a severidade.

Tanto na incidência quanto na severidade, os tratamentos inoculados com o fungo não apresentaram diferença entre os tempos de exposição, porém houve diferença quando estes foram comparados com os tratamentos sem inoculação (Tabela 4). Tanaka et al. (1989) observou aumento da incidência de C. gossypii var. cephalosporioides, em plântulas, conforme as sementes foram submetidas a diferentes períodos de exposição ao patógeno, chegando a $100 \%$ com 48 h de exposição, porém a avaliação foi realizada em placas de Petri, durante o teste de sanidade, ao invés do solo. Em trabalhos realizados com Colletotrichum lindemuthianum (Sacc. \& Magnus) Lams-
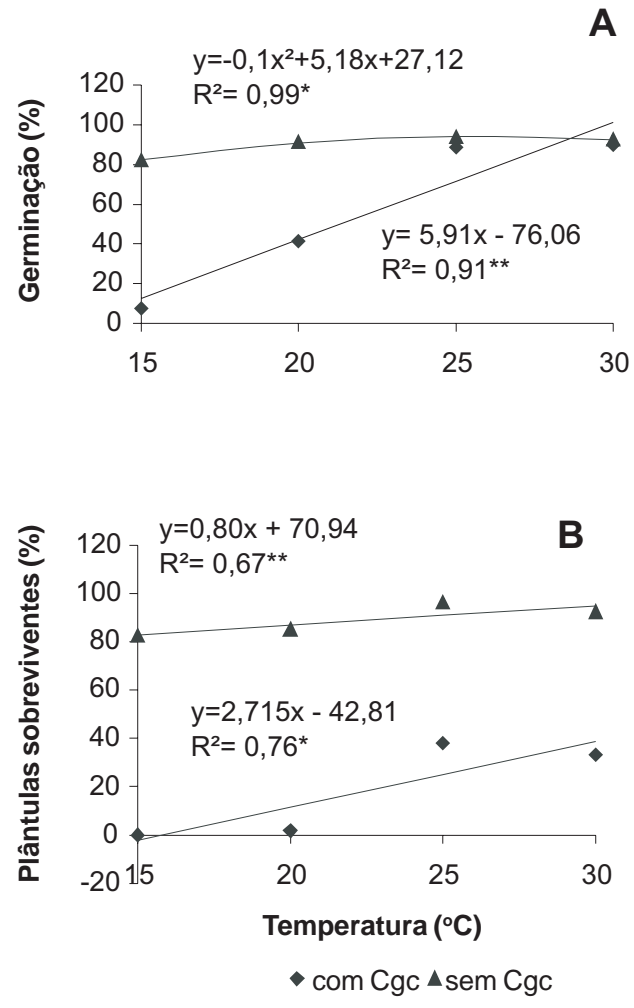

FIG. 1 - Influência da temperatura sobre a germinação de sementes de algodoeiro (Gossypium hirsutum) (A) inoculadas e não inoculadas com Colletotrichum gossypii var. cephalosporioides (Cgc) e sobre a porcentagem de plântulas sobreviventes (B).

Scrib., Carvalho (1999) avaliou a ocorrência de doença em plântulas emergidas em solo, e obteve aumento da incidência e da severidade da doença em função do aumento do tempo de exposição das sementes ao patógeno.

Apesar de não haver diferença entre os tratamentos, o maior tempo de exposição (108 h) apresentou menor incidência e severidade da doença. Esse fato pode está relacionado à menor porcentagem de germinação das sementes e morte de plântulas em pré-emergência discutidas anteriormente.

Entre os tratamentos provenientes de sementes não

TABELA 4 - Incidência e severidade da ramulose em plântulas de algodoeiro (Gossypium hirsutum) em função do tempo de exposição das sementes a Colletotrichum gossypii var. cephalosporioides (Cgc)

\begin{tabular}{lcclcc}
\hline \hline \multirow{2}{*}{$\begin{array}{l}\text { Tempo de } \\
\text { exposição (h) }\end{array}$} & \multicolumn{2}{c}{ Incidência (\%)* } & & \multicolumn{2}{c}{ Severidade (\%)* } \\
\cline { 2 - 3 } \cline { 5 - 6 } & com Cgc & sem Cgc & & com Cgc & sem Cgc \\
\hline 36 & 60,5 a A & 13,9 b B & & 55,1 a A & 14,8 b B \\
72 & 58,5 a A & 15,7 b B & & 53,5 a A & 14,0 b B \\
108 & 51,2 a A & 36,7 a B & & 47,8 a A & 29,8 a B \\
\hline CV (\%) & \multicolumn{2}{c}{30,32} & & \multicolumn{2}{c}{31,08} \\
\hline
\end{tabular}

*Médias com mesma letra, minúscula na coluna e maiúscula na linha, não diferem entre si pelo teste de Tukey $(\mathrm{P} \leq 0,05)$. 
inoculadas com o fungo, o tratamento 108 h de exposição ao meio com restrição hídrica apresentou maior incidência e severidade da doença. Provavelmente, a restrição hídrica favoreceu o desenvolvimento do patógeno na semente com o aumento do tempo de exposição (Tabela 4).

$\mathrm{Na}$ análise do efeito da temperatura nos tratamentos inoculados com o fungo observou-se menor incidência nas temperaturas de 15 e $20^{\circ} \mathrm{C}$ (Tabela 5). Essa baixa incidência pode está relacionada com a pressão de inóculo nas sementes e com as condições desfavoráveis ao desenvolvimento do hospedeiro, tendo como conseqüência, baixa germinação nestas temperaturas. Nas demais temperaturas, a doença afetou mais de $80 \%$ das plântulas (Tabela 5).

Da mesma forma, observou-se menor severidade da doença nas temperaturas de 15 e $20^{\circ} \mathrm{C}$ não havendo diferença entre os tratamentos inoculados e não inoculados com o fungo sendo, esta diferença, observada nas temperaturas de 25 e $30{ }^{\circ} \mathrm{C}$ com valores de $63 \%$ e $66,1 \%$, respectivamente (Tabela 5).

Observou-se aumento tanto da incidência quanto da severidade da doença quando a temperatura variou de 15 para $30{ }^{\circ} \mathrm{C}$ nos tratamentos inoculados com o fungo (Figura 2). A incidência e a severidade da doença progrediram afetando $89,8 \%$ e $80,9 \%$ das plântulas emergidas a $30{ }^{\circ} \mathrm{C}$, respectivamente (Figura 2). Sendo assim, a temperatura foi determinante no progresso da doença, pois a faixa de temperatura favorável para a ocorrência da doença encontrase entre 25 e $30{ }^{\circ} \mathrm{C}$ (Kimati, 1980). Nessas condições, considerando também a umidade relativa elevada, podem ocorrer grandes epidemias com altas taxas de progresso da doença no campo. O efeito da temperatura também foi testado na incidência e na severidade em outros patossistemas envolvendo o gênero Colletotrichum, com resultados semelhantes aos encontrados neste trabalho. Carneiro \& Amorim (1999) obtiveram maior severidade do mal-de-sete-voltas da cebola [C. gloeosporioides (Penz.) Penz. \& Sacc.] nas temperaturas de 25 e $30{ }^{\circ} \mathrm{C}$, sendo a severidade da doença proporcional ao aumento da temperatura no intervalo de 15 a $30^{\circ} \mathrm{C}$.

Apesar da não ocorrência de diferenças na incidência e na severidade da doença em função do inóculo, a presença

TABELA 5 - Incidência e severidade da ramulose em plântulas de algodoeiro (Gossypium hirsutum), provenientes de sementes inoculadas e não inoculadas com Colletotrichum gossypii var. cephalosporioides (Cgc), em função da temperatura

\begin{tabular}{|c|c|c|c|}
\hline \multirow{2}{*}{$\begin{array}{l}\text { Temperatura } \\
\left({ }^{\circ} \mathrm{C}\right)\end{array}$} & \multirow{2}{*}{$\frac{\text { Incidência }(\%)^{*}}{\text { com Cgc }}$} & \multicolumn{2}{|c|}{ Severidade $(\%)^{*}$} \\
\hline & & com Cgc & sem Cgc \\
\hline 15 & $7,3 \mathrm{~b}$ & $7,3 \mathrm{a}$ & $14,5 \mathrm{a}$ \\
\hline 20 & $41,2 \mathrm{a}$ & $32,7 \mathrm{a}$ & $41,1 \mathrm{a}$ \\
\hline 25 & $88,7 \mathrm{a}$ & $79,2 \mathrm{a}$ & $16,2 \mathrm{~b}$ \\
\hline 30 & $89,8 \mathrm{a}$ & $80,9 \mathrm{a}$ & $14,8 \mathrm{~b}$ \\
\hline CV $(\%)$ & 31,32 & \multicolumn{2}{|c|}{31,08} \\
\hline
\end{tabular}
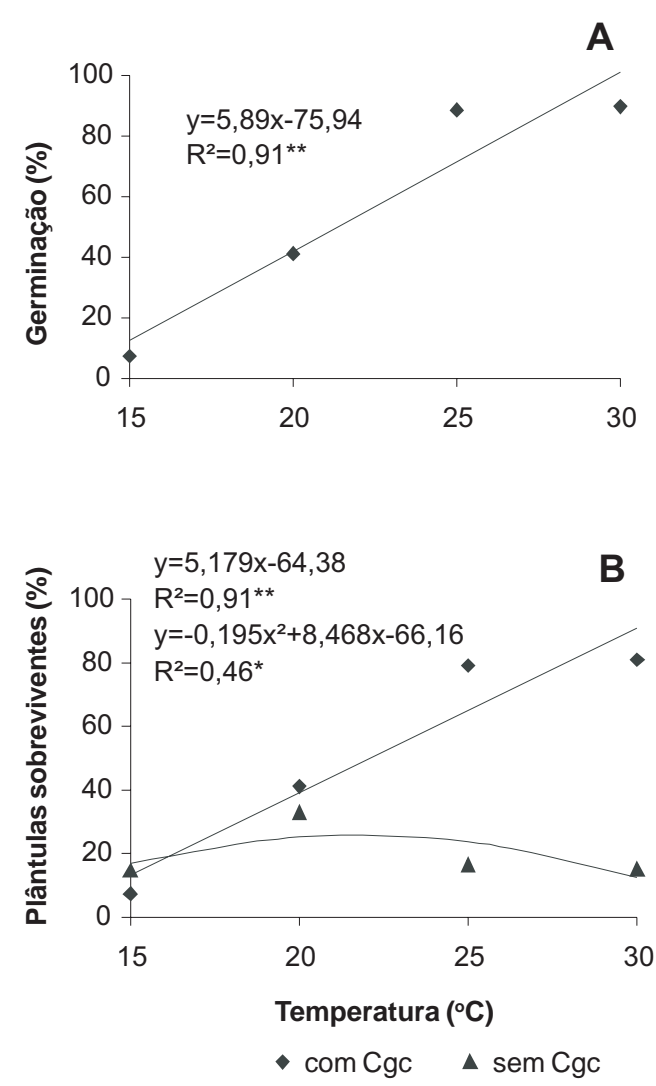

FIG. 2 - Influência da temperatura sobre a incidência (A) e a severidade (B) da ramulose em plântulas de algodoeiro (Gossypium hirsutum) provenientes de sementes inoculadas e não inoculadas com Colletotrichum gossypii var. cephalosporioides (Cgc).

do patógeno na área pode favorecer a ocorrência de epidemias em ciclos posteriores devido ao acúmulo de inóculo. É importante salientar que o nível de inóculo não deve ser utilizado como fator isolado para determinar a qualidade sanitária da semente, devendo-se levar em consideração, fatores relacionados ao ambiente, principalmente temperatura e umidade, e fatores intrínsecos a biologia do hospedeiro e do patógeno.

\section{AGRADECIMENTOS}

À Fundação de Amparo a Pesquisa de Minas Gerais pela concessão da bolsa de estudos para o curso de mestrado do primeiro autor.

Ao pesquisador Milton Geraldo Fuzzato do Instituto Agronômico de Campinas, pela valiosa colaboração em disponibilizar as sementes da linhagem NU 15.

\section{REFERÊNCIAS BIBLIOGRÁFICAS}

BEWLEY, J.D. \& BLACK, M. Seeds: physiology of development and germination. New York: Plenum Press, 1994. 
BRASIL. Ministério da Agricultura. Regras para análise de sementes. Brasília: LANARV/SNAD/MA, 1992.

CARNEIRO, L.C. \& AMORIM, L. Influência da temperatura e do molhamento foliar no monociclo do 'mal-de-sete-voltas' da cebola. Fitopatologia Brasileira 24:422-427. 1999.

CARVALHO, J.C.B. de. Uso da restrição hídrica na inoculação de Colletotrichum lindemuthianum em sementes de feijão (Phaseolus vulgaris L.). (Tese de Mestrado). Lavras. Universidade Federal de Lavras. 1999.

COSTA, M.L.N. Inoculação de Fusarium oxysporum f. sp. phaseoli em sementes de feijoeiro por meio da restrição hídrica. (Tese de Mestrado). Lavras. Universidade Federal de Lavras. 2000.

COSTA, M.L.N., MACHADO, J.C., GUIMARÃES, R.M., POZZA, E.A. \& ORIDE, D. Efeito de Fusarium oxysporum f. sp. phaseoli no desempenho de sementes de feijoeiro infectadas artificialmente. Resumos, $7^{\circ}$ Simpósio Brasileiro de Patologia de Sementes, Sete Lagoas, MG. 2002. p.42.

FERREIRA, D.F. Análises estatísticas por meio do SISVAR para Windows versão 4. 0. Resumos, 45 ${ }^{\mathrm{a}}$ Reunião Anual da Região Brasileira da Sociedade Internacional de Biometria, São Carlos, SP. 2000. p.235.

KIMATI, H. Doenças do algodoeiro - Gossypium spp. In: Galli. F. (Ed.) Manual de Fitopatologia. São Paulo, 1980. pp.28-48.

MACHADO, J.C., CARVALHO, J.C.B., VIEIRA, M.G.G.C. \& GUIMARÃES, R.M. Methodology for infecting seeds by fungi using water restriction technique. Abstracts, $26^{\circ}$ International Seed Testing Congress-seed Symposium. Angers, France. 2001. p.62.

MACHADO, A.Q. \& MACHADO, J.C. Estudo da relação entre o potencial de inóculo de Fusarium verticillioides (syn. F. moniliforme) e o desempenho inicial de sementes de milho por meio da técnica de restrição hídrica. Resumos, $7^{\circ}$ Simpósio Brasileiro de Patologia de Sementes, Sete Lagoas, MG. 2002. p. 453.

MAUDE, R.B. Seedborne diseases and their control - Principles; practice. New York: CAB International, 1996.

McKINNEY, H.H. Influence of soil temperature and moisture on infection of wheat seedlings by Helminthosporium sativum. Journal Agricultural Research 26:195-219. 1923.

MICHEL, B.E. \& RADCLIFFE, D. A computer program relating solute potencial to solution composition for five solutes. Agronomy Journal, Madison 87:131-136. 1995.

NUNES, U.R., SANTOS, M.R., ALVARENGA, E.M. \& DIAS, D.C.F.S. Efeito do condicionamento osmótico e do tratamento com fungicida na qualidade fisiológica e sanitária de sementes de cebola (Allium cepa L.). Revista Brasileira de Sementes 22:239246. 2000.

PRADO, P.E.R., MACHADO, J.C., CARVALHO, E.M. \& SOUSA, M.V. Eficácia do tratamento químico de sementes de algodão em relação ao potencial de inóculo de Colletotrichum gossypii var. cephalosporioides. Resumos, $7^{\circ}$ Simpósio Brasileiro de Patologia de Sementes, Sete Lagoas, MG. 2002. p.453.

SHAH, D.A. \& BERGSTROM, G.C. Epidemiologia e manejo de patógenos transmitidos por sementes, com ênfase nos fungos que formam picnídios. Revisão Anual de Patologia de Plantas 8:339365. 2000.

TANAKA, M.A.S. \& MACHADO, J.C. Patologia de sementes. Informe Agropecuário 11:40-46. 1985.

TANAKA, M.A.S., MARIANO, M.I.A. \& MENTEN, J.O.M. Inoculação artificial de sementes de algodão com Colletotrichum gossypii var. cephalosporioides e infecção das sementes em função do tempo de exposição ao patógeno. Summa Phytopathologica 15:232-237. 1989.

TANAKA, M.A.S. \& MENTEN, J.O.M. Comparação de métodos de inoculação de sementes de algodoeiro com Colletotrichum gossypii var. cephalosporioides e C. gossypii. Summa Phytopathologica 17:219-226. 1991.

TANAKA, M.A.S. Patógenos causadores de tombamento do algodoeiro e seus efeitos sobre a germinação das sementes em diferentes temperaturas. Fitopatologia Brasileira 19:29-33. 1994.

TANAKA, M.A.S. Transmissão planta-semente e sementeplântula do agente causal da ramulose do algodoeiro. In: Menten, J.O.M. (Ed.) Patógenos em sementes: detecção, danos e controle químico. Piracicaba. Escola Superior de Agricultura Luiz de Queiroz/FEALQ, 1995. pp.171-178.

VALARINI, P.J. \& MENTEN, J.O.M. Inoculação artificial de sementes de feijão com Xanthomonas campestris pv. phaseoli e seu efeito sobre a qualidade sanitária e a germinação. Summa Phytopathologica 17:227-231. 1991. 